\title{
College Students' Professional Ability Training Based on the Theory of Competency
}

\author{
Yingxia $\mathrm{Yu}^{1, \mathrm{a}}$, Jingfeng Sheng ${ }^{1, \mathrm{~b}}$ and Bolin $\mathrm{He}^{2, \mathrm{c}}$ \\ ${ }^{1}$ School of Transportation \& Logistics, East China Jiaotong University, Nanchang 330013, China \\ ${ }^{2}$ School of Mechanical \& Electrical Engineering, East China Jiaotong University, Nanchang, 330013 \\ China \\ ayyxhbl@163.com, b604972053@qq.com, chebolin@163.com
}

Keywords: competency; competency models; college students' career planning; professional competency.

\begin{abstract}
The aim of this study was to promote college students' professional ability. The competency model of college students has been analysed and researched. Combined with the characteristics of college students and the professional training status, the relevant theoretical approaches of college students competency model were analysed and summarized, too. It will provide a new idea and method for the professional ability training building of the competency model of college students. Proposals have been offered based on the theory of competency. It is necessary to construct different competency models for different professions, and then make the professional training plans according to the competency models, meanwhile dynamic monitor students' professional competency.
\end{abstract}

\section{Introduction}

Competency has been derived from the Latin "Competere”. In 1973, Harvard university professor McClelland put forward the concept of "Competency" for the first time in "Testing for Competence Rather than for Intelligence”, and also put forward a new evaluation method of employee performance at the same time, that is "Behavioral Event Interview" ${ }^{[1]}$. Then it obtained good effect in the practical application of enterprises, but research impplies the university personnel training were rare.

Nowadays, the research on quality education among domestic universities mainly focuses on quality education's connotation, structure, system, related policies, curriculum system reformation and the research on some specific quality, such as scientific and cultural quality, information literacy. However, people with different majors or careers need different talent quality and different training pattern.

Competency is an efficient way and has gradually been recognized in human resource management field, that some developed countries have closely connected it with education, and good results have been achieved in practice. Competency model is concentrated reflection of competency; recently it is mainly applied in management, psychology and other related fields, which has obtained significant achievement. But in the field of quality education, it is still short of competency, and the model does not reflect the characteristics of college students. Thus, to build competency model and to reform personnel training mode, which can target to selecting, training talents in different majors and careers, it is necessary to broaden research approach and provide practice guidance of professional quality education.

\section{The Theory of Competency}

\subsection{The Connotation of Competency}

McClelland pointed out that competence related directly to job performance and other important achievements in life, and can distinguish the good from the average in performance. It shows knowledge, skill, ability, traits and motives ${ }^{[1]}$. And then this concept was gradually recognized and 
applied by many scholars and practitioners. On the basis of it , many different understandings for competence connotation were brought.

Guglielmino pointed out that competence shows three aspects. The first one is the conceptual competence, including decision-making ability, the innovation ability, ability to think. The second one is the interpersonal competence, including communication, leadership skills, negotiation and attitude of growth. The last one is the skill competence, including abilities in planning personal career and in charge of self-time.

The concept of competency is no unified up to now. There are two main views, one is the view of characteristics, and the other is the view of behavior. The view of characteristics thinks competency is potential and persistent characteristics that can distinguish the good from the average in performance, including motives, traits, self-concept, interest, attitude, values, knowledge and skill ${ }^{[1-3]}$. The view of behavior thinks competency is the overt behavior characteristics that are specific, observable, verifiable and categorized $^{[4,5]}$.

Although there were controversies about the concept of competency in academia, there is consensus among the following three aspects:

(1)The behavior of the individual is an expression form the degree of competency. This behavior has observability and measurability, and it is that motives, ability, attitude, knowledge were applied in a scenario for a particular goal.

(2) Competency is targeted. It is related to work situation, specific jobs position. In an organization, content and level of competence in the different positions are different. In different organizations and different industries, nor content and level of competence in the same or similar jobs are completely different ${ }^{[6,7]}$.

(3)The competency is closely related to the job performance and enterprise performance. The different elements of competency have different effects on the different components of performance, but there are significant differences in different industries ${ }^{[8]}$.

(4)The competency is not static. It will change along with the change of the individual experience, career stage and age, and be improved by training and learning ${ }^{[9]}$.

\subsection{Competency Structure Model}

Competency model is the competency of structure form, used for describing the combination of different competency elements in order to achieve the specific performance targets or complete a $\operatorname{task}^{[10]}$. Anntoinette D. answered the two questions in "The Art and Science of Competency Models: Pinpointing Critical Success Factors”, one is which skills, knowledge and personality characteristics needed to complete various tasks, the other one is which behavior to directly affects the improvement of performance and the success of the work ${ }^{[11]}$. At present, the representative competency models are "Iceberg Competency Model "and "Onion Competency Model”.

Competency is divided into "iceberg above part" and "an iceberg in the following sections" in "Iceberg Competency Model", as shown in Fig. $1^{[2]}$. "iceberg above part" is the external expression easy to observe, measure and evaluate, including the basic knowledge, basic skills, etc. It can be changed easily through education and training, etc. "an iceberg in the following sections" is the inner part difficult to observe, measure and evaluate, including social roles, self-image, personality traits and motive. They play a very important role in the person's behavior and performance, but not easy to change by the influence of the outside world. It shows that man's inner factors are important to them.

Richard Boyatzis ${ }^{[3]}$ came up with "Onion Model” based on the theory of McClelland competency, as shown in Fig. 2. The competency model from inside to outside is summarized as layer upon layer similar to the structure of onion. At the core of "Onion Model" is motive, extend social roles, knowledge, skills, and attitudes outward from the core. Competency to the outer layer more and more easily developed and changed by acquired means. And to the inner layer, the more difficult to be acquired, also to be evaluated.

But no matter which kind of model is essentially the same. It includes two parts, one is the explicit characteristics, such as the skills and knowledge, secondly, the deep features, such as social roles, 
self-image and motive, etc. ${ }^{[12]}$. In contrast, "Onion Model” more highlights the hierarchical relationships of intrinsic competency and apparent one.

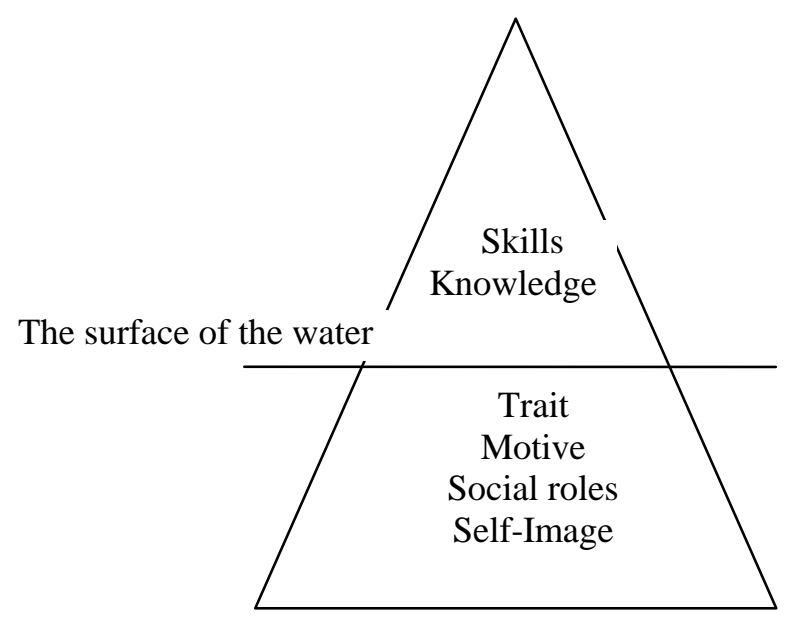

Fig. 1 Iceberg Competency Model

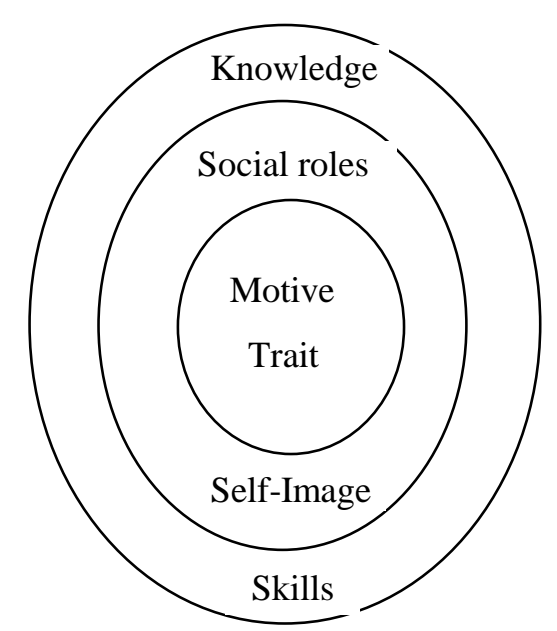

Fig. 2 Onion Competency Model

\section{College Students' Professional Ability Training}

Chinese scholars have begun to research into competency from the 1980s, especially in researching enterprise human resource management. The few has not studied on vocational quality education in colleges. For example, what are the core ability and competency of different professional college students?

\subsection{The Construction of Post Competency Model}

The process of building competency models is the process of refining the core index. Colleges and universities, or the competent department of education should be in line with enterprise, build all kinds of competency model what has the characteristics of industry, professional characteristics and job characteristics and effect factors of college students' competency.

The process of building post competency model should be considered a kind of the black box model about data extraction and analysis. It includes input competency, competency extract and output competency, as shown in Fig. 3.

First, we should determine the extraction method of competency, and then observe all kinds of feedback, analyze the output information, establish a competency standard. Secondly, test to judge and build competency model.

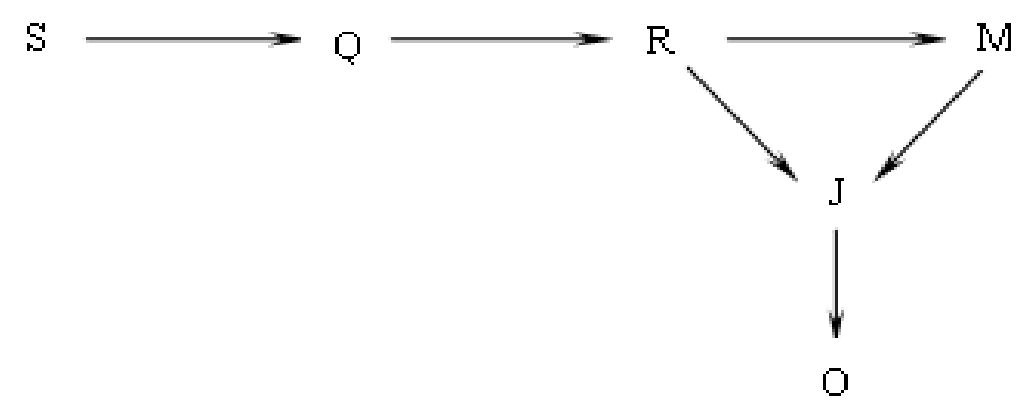

Fig. 3 The Process of Building Post Competency Model

Where $\mathrm{S}$ is input information, $\mathrm{Q}$ is competency extraction, $\mathrm{R}$ is output information, $\mathrm{M}$ is competency standard, $\mathrm{J}$ is analysis and evaluation, and $\mathrm{O}$ is competency model. 


\subsection{College Students' Career Planning}

Job analysis is the important process of college students' career planning, and post competency is the necessary content of job analysis. Different from traditional job analysis paying attention to work elements, job analysis based on competency models focuses on behavior and characteristics of outstanding persons. Job specification and job description based on this kind of behavior or trait will be able to more accurately predict future job performance ${ }^{[13]}$.

The effectiveness of the proposed can greatly improve planning using the theory of competency in students' career planning. It makes the students understand the professional competency requirements in the future and the target in learning phase. Because the competence embodies the quantitative information, behavior and character can be measured. It can improve the objectivity and accuracy of detection. It is determined usually based on enterprise's strategic goals, values and business philosophy, so it is able to avoid limitations and short sight in general planning analysis. At the same time, it will change the content and value orientation of the planning and analysis work from the process to the results, and performance will be a measurement standard of work competency. It ensures that the college students multi-dimensional match future job in the skills, abilities, values, goals and so on. It ensures the students post competence for the future.

\subsection{Professional Ability Training}

The professional training mode traditionally takes operating skills, explicit knowledge and other external factors as a training program, and pays insufficient attention to students' inner qualities. A competency model provides a new perspective for the students' training. It pays attention to students' individual values, potential and characteristics.

Post competency model plays an important role in the training ${ }^{[14]}$. The first step of training is training needs analysis, and the gap between ideal performance and actual performance is the basis and the purpose of requirements analysis. Universities develop the professional training plan to determine the training content in accordance with the model. In addition to the knowledge, skills showing features outside, the professional training plan should cover the deep competency thereof. In the process of implementation of training plan, the school also may dynamic monito student's competency, obtain the information of students' competency level in time, master the gap between student's competency and post competency model, repair plan targeted, gradually improve.

\section{Conclusion}

Post competency is refining and application about enterprise's performance prominent traits and behaviors. It can be a reference that students improve learning performance. Students can better understand the advantages and disadvantages of self, increase active and self-consciousness to improve the performance. Moreover, students are to be near post competency standards at the same time, can make appropriate adjustments to the career planning. It prompts them to invest more professional learning enthusiasm.

Competence model can help college students clear their own professional knowledge and skills, and realize their own career planning.

\section{Acknowledgment}

The work is supported by the education scientific planning project of Jiangxi Province (16YB062) and the degree and postgraduate education teaching reform project of Jiangxi province (JXYJG-2014-081).

\section{References}

[1]. David C, McClelland. Testing for competence rather than for intelligence[J]. American Psychologist, 1973, 35(2): 19-20. 
[2]. Spencer L M,Spencer S M. Competence at work: Models for superior performance[M]. New York: John Wdey \& Sons,lnc.,1993.

[3]. Boyatzis RE. The Competent Manager: A Model for Effective Performance[M]. New York: John Wiley \& Sons,Inc.,1982.

[4]. Fletcher S. NVOs, standards and competence: A practice guide for employers management and trainers[M]. London: Kogan,1992.

[5]. Zhong Lifeng, Shi Kan. The new progress in the study of competence characteristics[J]. Nankai Business Review, 2003(2):4-8.

[6]. Parry S B. Just what is a competency? And why should you care?[J]. Training, 1996,35(6): 58-60.

[7]. Mirabile R J. Everything you wanted to know about competency modeling[J]. Training \& Development, 1997,51 (8):73-77.

[8]. Sandberg J. Understanding human competence at work: an interpretative approach[J]. Academy of Management Journal.2002,43(1): 9-25.

[9]. Byham W C. Moyer RP. Using competencies to build a successful organization[J]. Development Dimensions International,Inc., 1996.

[10]. McLagan Patricia, Nel Christo. A new leadership style for genuine total quality[J]. Journal for Quality \& Participation, 1996,19: 14.

[11]. Sanchez J., Anntoinette D., Lucia, Richard Lepsinger. The Art and Science of Competency Models: Pinpointing Critical Success Factors[J]. Personnel Psychology, 2000, 53: 509-511.

[12]. Hu Yanxi, Guan Zhihua. The study of competency model both at home and abroad[J]. Market Modernization, 2008,11:248.(In Chinese)

[13]. Zhang Keren. Introduction to human resource system of post competency model[J]. Modern Economic Information, 2012, (04): 63.(In Chinese)

[14]. Wang Hui. The establishment of the competency model in Enterprise human resources management[J]. Human Resource Management. 2012,(05): 42-43.(In Chinese) 